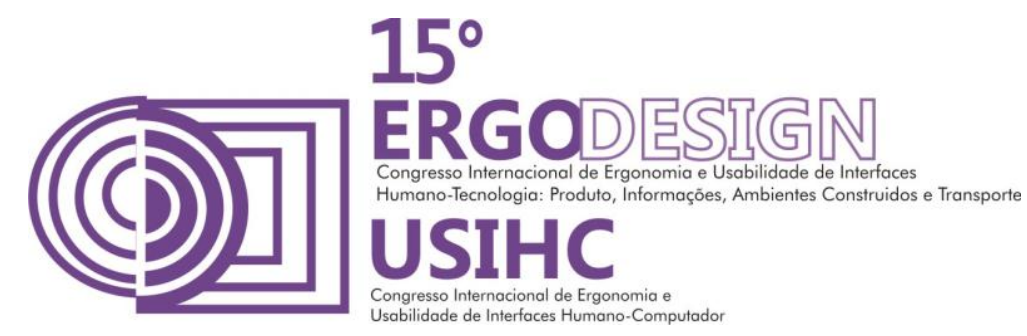

\title{
CONSIDERATION OF VARIABLES AND SELECTION OF PARAMETERS TO STUDY LIGHT PHENOMENA IN SCHOOL ENVIRONMENTS NATURALLY ILLUMINATED THROUGH OPENWORK WALLS IN THE TROPIC
}

\author{
OSPINA BETANCUR, Daniela (1); \\ PARRA CORREA, Elizabeth (2) \\ (1) Universidad Nacional de Colombia, Architecture student \\ e-mail:daospinabe@unal.edu.co \\ (2) Universidad Nacional de Colombia, Architecture student \\ e-mail:elparracor@unal.edu.co
}

\begin{abstract}
The openwork walls are representative architectural devices from tropic as they allow the passage of air and light while mitigating the adverse effects of the sun, school environments are among the areas that have adopted this solution. This research focused on the creation of a scenario under ideal conditions which projects draw conclusions that allow reflection on geometric strategies for improving the luminous performance of openwork walls, to this effect shooting was done at a physical model scale under real sky conditions.
\end{abstract}

\section{INTRODUCTION}

The openwork walls have been widely used in the institutional architecture for allowing constant air flow in warm climates while attenuating the solar raid, in addition to its easy maintenance and quantity production. This has resulted in educational settings are lit by openwork walls, suggesting reflect on the high visual demands of the activities taking place within school environments such as are read, write, recognize colors, among others and more important when it comes to children learning by imitation activities like reading.

One factor that affects the visual ergonomics experienced by users is the natural light. The present study aimed choosing parameters that allowed the construction of a physical scale model to study visual phenomena in naturally lit through openwork walls in school environments; the benefit that the research brings by shooting is permitted to study light phenomena and generate strategies to improve the conditions of visual ergonomics users, the choice of a physical model allowed to know the lighting behavior within the classroom under real sky, involvement of students, furniture, materials and their properties. 


\section{THEORETICAL FRAMEWORK}

In the documents reviewed, we found information about school environments, openwork walls and some light phenomena as glare and distribution of natural light; nevertheless in any case all variables are combined. Similarly they are important because they allow an approach to boarding methodologies on topics of interest to the investigation.

The article Salazar (1934-7359) opens a wide panorama regarding openwork walls, its geometry, how to perform experiments and methodological monitoring that can yield clears results. $^{1}$

Colombian Technical Standard (Norma Técnica Colombiana) 4595 only refers to the issue of visual comfort as to the amount of light and viewing angles that should be in school environments, this does not guarantee that the lighting conditions are optimal to leave out other phenomena lighting can affect visual comfort such as glare and contrast. ${ }^{2}$

Bedoya and Ruttkay makes the comparison with the standard and conclude that this falls short regarding it does not consider the environmental, human and real habitability factors, despite ensuring optimal lighting conditions. ${ }^{3}$

\section{SELECTION OF PARAMETERS}

In order to construct a hypothetical model in ideal conditions and based on this a physical scale model that allows control variables, it started by choosing a number of parameters in order to limit them which were grouped into the following categories:

a) Colombian Technical Standard (Norma Técnica Colombiana) 4595 served as a guide for choosing the dimensions, geometry and orientation of the classroom; also the number of students, the distance to the board and the opening area of optimal lighting vain as shown in picture 2.

b) To determine the height of the line of sight and the work plane were considered body dimensions of the various percentiles by age. In the sample line of sight was averaging visual ranges of men and women 15 years of percentiles 5, 50 and 95 . The resulting averaged $1.15 \mathrm{~m}$ from the floor. Picture 2

c) The orientation of the facade was chosen based on two parameters, one suggested by the Colombian Technical Standard (Norma Técnica Colombiana) 4595 to guide the openings in north or south direction and the other to avoid direct sun raid on jobs throughout the year, for which the most critical condition for the month of December in the south facade that was chosen. Picture 1

d) In the election of openwork element used were taken into consideration two factors: the biggest step that would allow natural light and simultaneously will control the solar raid. Two

1 SALAZAR TRUJILLO, Jorge Hernan. Openwork walls and their solar applicability range. Journal of civil engineering and architecture. November 2012. Volumen-6, No. 11. ISSN 1934-7359, USA.

${ }^{2}$ Instituto Colombiano De Normas Técnicas Y Certificación. Planeamiento y diseño de instalaciones y ambientes escolares. NTC 4595. 1999. 45p

${ }^{3}$ BEDOYA JARAMILLO, Carolina. Alterações Na Distribuição Da Luz Natural Causados Pelos Agrupamentos De Estudantes Em Salas De Aula. Master in Architecture and Urbanism. Universidad Federal de Santa Catarina. 2014. 167 p. 


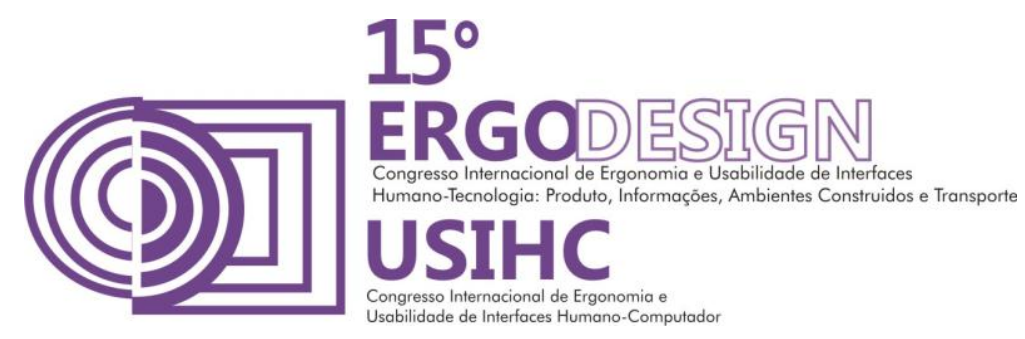

types of openwork mark were chosen and placed in horizontal strips as required to control solar raid. Picture 1

e) The different cones of vision and its various applications; daily activities that happen in a school environment such as looking at the board, the workplace and the partner and the relationship of these two factors with illuminated surfaces are essential principles in the analysis of visual phenomena and its effect on visual ergonomics users. Picture 2
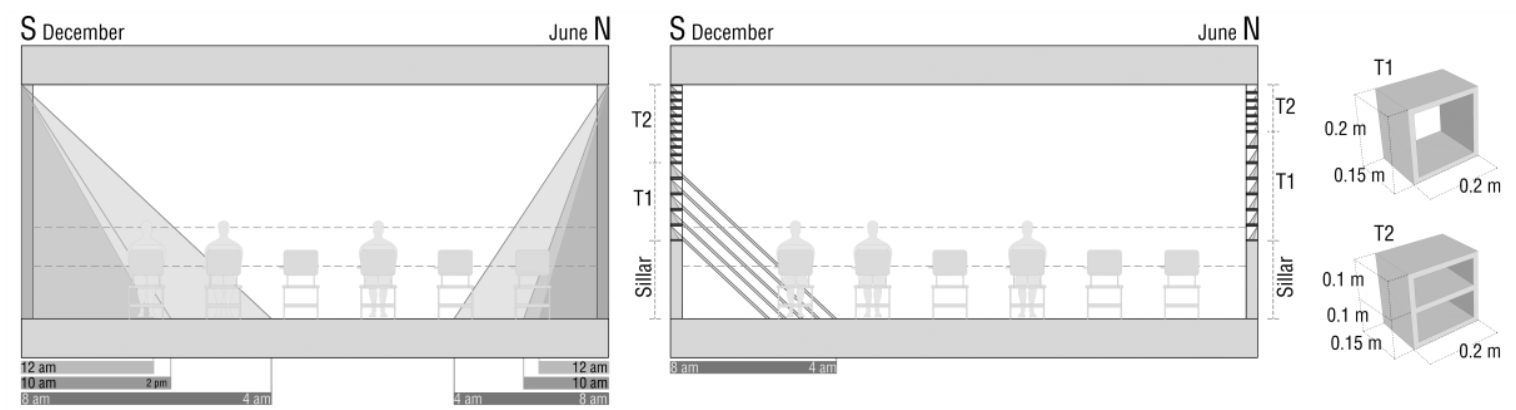

Picture 1. Control of solar raid with openwork walls for December and June in latitude 6.26N
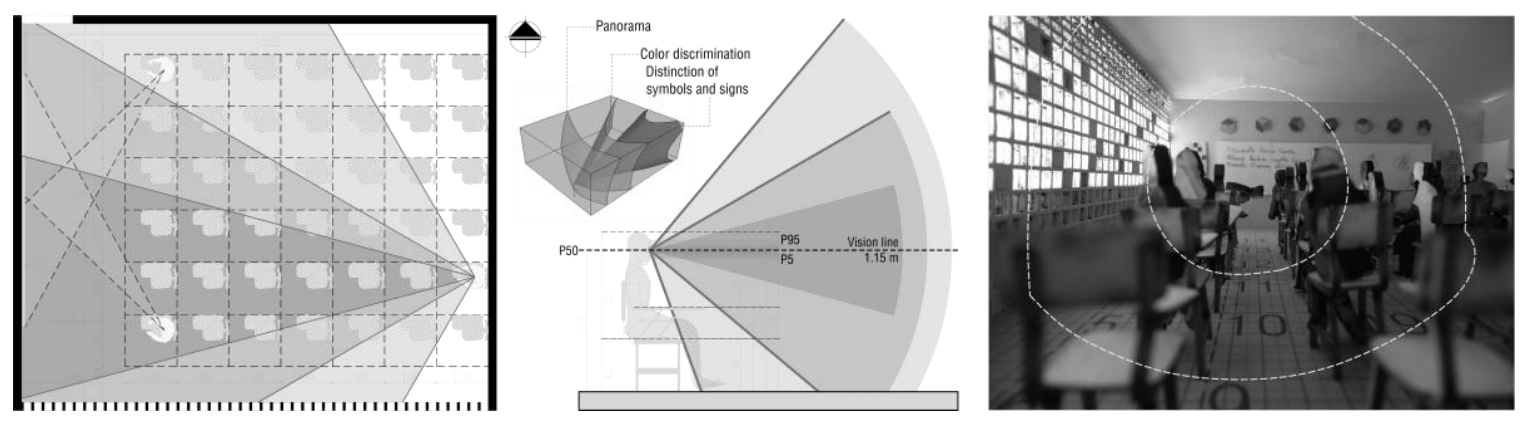

Picture 2. Projection of visual cones in physical model of the classroom under ideal conditions.

\section{CONCLUSIONS AND PROJECTION OF RESEARCH}

In Chapter 7.2 of the Technical Standard Colombiana (Norma Técnica Colombiana) 4595 referred to the visual comfort in school environments, there are no visual ergonomics considerations beyond the suggested illuminance levels according to use in this regard are outside factors such as age, occupancy models, furniture, users and how they alter the income and distribution of natural light. The physical scale model allowed us to consider the involvement of these factors and by photography tools like observing made evident the behavior of light in different conditions, allowing the recognition of light phenomena varying levels of visual ergonomics.

Another useful tool provided by the present investigation is the relationship of visual cones to certain activities in the classroom; this superimposed on photo tool can be useful to identify problems or opportunities that may develop in future research. 